\title{
Title:
}

\section{ICE1 Ser403 is necessary for protein stabilization and regulation of cold signaling and tolerance}

Kenji Miura $^{\mathrm{a}, \mathrm{b}, 1,2}$, Masaru Ohta ${ }^{\mathrm{a}, 1}$, Machiko Nakazawa ${ }^{\mathrm{a}}$, Michiyuki Ono ${ }^{\mathrm{a}}$, and Paul M.

Hasegawa $^{\mathrm{b}}$

${ }^{\mathrm{a}}$ Graduate School of Life and Environmental Sciences, University of Tsukuba, Tsukuba 305-8572, Japan

${ }^{\mathrm{b}}$ Center for Plant Environmental Stress Physiology, Purdue University, West Lafayette, IN 47907, USA

${ }^{1}$ K.M. and M.O. contributed equally to this work

${ }^{2}$ Corresponding author: Kenji Miura

Address: Graduate School of Life and Environmental Sciences, University of Tsukuba, Tsukuba 305-8572, Japan

Email, kmiura@gene.tsukuba.ac.jp; TEL \& Fax, +81-29-853-6401

Running title: Stabilization and regulation of ICE1 by serine 403

Key words: cold tolerance, cold signaling, transcription factor, stabilization, ubiquitylation, substitution

Word count: 5685 


\section{Summary}

ICE1, a MYC-type transcription factor, has an important role in the induction of $C B F 3 / D R E B 1 A$ for the regulation of cold signaling and tolerance. In this study, we reveal that serine 403 of ICE1 is involved in regulating the transactivation and stability of the ICE1 protein. Substitution of serine 403 to an alanine enhanced the transactivational activity of ICE1 in Arabidopsis protoplasts. The overexpression of ICE1(S403A) conferred more freezing tolerance than ICE1(WT) in Arabidopsis, and the expression of cold-regulated genes such as CBF3/DREB1A, COR47, and KIN1 was enhanced in ICE1(S403A)-overexpressing plants. Furthermore, the ICE1(S403A) protein level was not changed after cold treatment, whereas the ICE1(WT) protein level was reduced. Interestingly, polyubiquitylation of the ICE1(S403A) protein in vivo was apparently blocked. These results demonstrate that serine 403 of ICE1 has roles in both the transactivation and the cold-induced degradation of ICE1 via the ubiquitin/26S proteasome pathway, suggesting that serine 403 is a key residue for the attenuation of cold stress responses by HOS1 mediated degradation of ICE1.

Abbreviations: bHLH, basic helix-loop-helix; CBF, CRT-binding factor; CRT, C-repeat; DRE, dehydration responsive element; DREB, DRE-binding protein; HOS1, high expression of osmotically responsive genes 1; ICE1, inducer of CBF expression 1; SUMO, small ubiquitin-related modifier 


\section{Introduction}

Plants need to adapt to changes in the environment for their survival. When the temperature decreases to below the freezing point, some plants native to temperate zones have the ability to tolerate the freezing temperature. The freezing tolerance of temperate plants is not a constant property but it is induced by exposure to non-freezing low temperatures. This process is known as cold acclimation (Guy, 1990; Thomashow, 1999). Global transcription profiling analyses have revealed that more than $10 \%$ of the genes in the Arabidopsis genome are regulated during cold acclimation (Fowler and Thomashow, 2002; Kreps et al., 2002; Seki et al., 2002). These cold-responsive genes include key metabolic enzymes, late embryogenesis-abundant proteins, and detoxification enzymes (Thomashow, 1999).

Many cold- and dehydration-responsive genes contain one or more copies of C-repeat (CRT)/dehydration responsive element (DRE) cis-elements in their promoters. The CRT/DRE cis-element has a core sequence, CCGAC, and is able to respond to cold, dehydration and salinity. (Baker et al., 1994; Yamaguchi-Shinozaki and Shinozaki, 1994). A family of AP2-type transcription factors, known as the CBF (CRT-binding factor)/DREB (DRE-binding protein) family, binds to these cis-elements and induces expression of the cold- and dehydration-responsive genes (Stockinger et al., 1997; Liu et al., 1998). Thus, the ectopic expression of $C B F / D R E B$ confers improved tolerance to freezing, dehydration and salinity (Jaglo-Ottosen et al., 1998; Liu et al., 1998). Because the expression of $C B F / D R E B$ itself is induced by cold (Stockinger et al., 1997; Liu et al., 1998; Gilmour et al., 1998), other transcription factors also control the induction of $C B F / D R E B$ in response to low temperature.

Several factors involved in the regulation of $C B F / D R E B$ expression have been 
identified genetically in Arabidopsis (Chinnusamy et al., 2007; Lissarre et al., 2010). The ice 1 mutant has been identified by a genetic screen of mutants impaired in the expression of the CBF3-LUC reporter gene (Chinnusamy et al., 2003). Expression of $C B F 3 / D R E B 1 A$ and its downstream target genes was shown to be down-regulated in the ice1 mutant, and, consequently, ice 1 plants display significantly reduced chilling and freezing tolerance (Chinnusamy et al., 2003). ICE1 (inducer of CBF expression 1) encodes a MYC-like bHLH (basic helix-loop-helix) transcription factor that can bind directly to the canonical MYC cis-elements (CANNTG) in the CBF3/DREB1A promoter (Chinnusamy et al., 2003). A genome-wide transcription profile revealed that the expression of 204 of the 939 cold-regulated genes is affected in the ice 1 mutant (Lee et al., 2005). Although ICE1 mainly affects CBF3/DREB1A expression (Chinnusamy et al., 2003), ICE2, a homolog of ICE1 (At1g12860), primarily influences the expression of CBF1/DREB1B, but not of CBF3/DREB1A (Fursova et al., 2009). Thus, ICE1 and ICE2 have pivotal roles in the transcriptional regulation of $C B F / D R E B s$. Interestingly, ICE1/SCREAM is also involved in stomatal differentiation (Kanaoka et al., 2008), suggesting that ICE1 links the transcriptional regulation of environmental adaptation and stomatal development in plants.

The recessive mutant hos1 causes the enhanced expression of $C B F / D R E B$ and cold-responsive genes in cold conditions (Ishitani et al., 1998; Lee et al., 2001). HOS1 (high expression of osmotically responsive genes 1) encodes a RING finger-type E3 ligase for the ubiquitylation of ICE1, which results in the cold-induced degradation of ICE1 (Lee et al., 2001; Dong et al., 2006). ICE1 is also post-translationally regulated by SUMO (small ubiquitin-related modifier) E3 ligase SIZ1-mediated sumoylation (Miura et al., 2007a; Miura et al., 2007b; Miura and Hasegawa, 2010). Protein 
phosphorylation is the most common mechanism controlling gene expression, however, it is unknown whether ICE1 is also regulated by this modification.

In this study, we evaluated the serine/threonine residues in the regulation of ICE1. The substitution of S403 to alanine in ICE1 [ICE1(S403A)] enhanced GAL4-mediated transactivation in protoplasts, the expression of cold-regulated genes, such as CBF3/DREB1A, COR47, and KIN1, and cold tolerance in transgenic plants. Furthermore, the ICE1(S403A) protein level was not changed after cold treatment, whereas the ICE1(WT) level was reduced. Polyubiquitylation of the ICE1(S403A) protein was blocked in vivo. These results demonstrate that S403 of ICE1 plays a role in the regulation of both the transactivation and the cold-induced degradation of the transcription factor via the ubiquitin/26S proteasome pathway, probably mediated by HOS1. Thus, the enhanced transactivation and impaired degradation of ICE1(S403A) may enhance the expression of CBF3/DREB1A and its regulon genes in ICE1(S403A)-overexpressing plants. 


\section{Results}

Serine 403 to alanine substitution increases the transactivation activity of ICE1 and the freezing tolerance of Arabidopsis

Previously, we have demonstrated that the SIZ1-mediated sumoylation of ICE1 at K393 is necessary for cold signaling and tolerance (Miura et al., 2007a) and that the flanking region of the sumoylation site, including serine and threonine residues, is highly conserved among orthologs. Several reports have also demonstrated relationship between phosphorylation and sumoylation (Mohideen et al., 2009). Consequently, separate variant proteins with S to A or T to A mutations were generated; T387A, S389A, S399A, S400A or S403A (Fig. 1A). These ICE1 variants were fused with the DNA-binding domain of the yeast GAL4 transcription factor (Fig. 1B; Ohta et al., 2000; Tiwari et al., 2003). Each GAL4-ICE1 variant was co-introduced into Arabidopsis leaf protoplasts with the GAL4-GUS reporter and 35S-LUC (Fig. 1B), and the protoplasts were incubated at $23^{\circ} \mathrm{C}$. Because of the moderate temperature, we presumed that ICE1 variant would not have been degraded by the proteasome (Dong et al., 2006). The transactivation activity was measured as GUS activity and LUC activity was used for plasmid uptake normalization between samples (Tiwari et al., 2003; Yoo et al., 2007). GAL4-ICE1(S403A) and GAL4-ICE1(S399A, S400A, S403A) activated GAL4-mediated transactivation $\sim 2.8$-fold higher than GAL4-ICE1(WT) did (Fig. 1C; Supplemental Fig. S1). In contrast, the transactivation activities of ICE1(T387A), ICE1(S389A), and ICE1(S399A or S400A) were similar to that of ICE1(WT) (Supplemental Fig. S1). These results indicate that S403 is an important residue in the negative regulation of ICE1 transactivational activity. 
In order to assess the biological role of S403 in ICE1, we produced transgenic plants overexpressing ICE1(S403A). Transcript abundance of the ICE1(S403A) transgene was evaluated by semi-quantitative RT-PCR analysis (Supplemental Fig. S2), which indicated that transgenic gene expression was similar in ICE1(WT) (line \#12; Miura et al., 2007) or ICE1(S403A) (\#5, 12, 13) transgenic plants. Non-acclimated three-week-old wild-type (Col-0), a vector control, ICE1(WT)-overexpressing (Miura et al., 2007a), and ICE1(S403A)-overexpressing plants were subjected to $-4^{\circ} \mathrm{C}$ for $4 \mathrm{~h}$. ICE1(WT)-overexpressing plants exhibited higher survival rates $(9.38 \% \pm 6.0)$ than wild-type $(3.13 \% \pm 1.8)$ and vector control (all died under this condition) plants after one week of recovery at room temperature (Fig. 2A and 2C). The ICE1(S403A)-overexpressing plants were more freezing tolerant than the ICE1(WT)-overexpressing plants (survival rates ranging from $34.4 \%$ to $45.3 \%$, with statistical significance at $P<0.05$ against the survival of ICE1(WT)-overexpressing plants; Fig. 2C). Similar results were also observed when cold-acclimated plants were subjected to $-8^{\circ} \mathrm{C}$ for $4 \mathrm{~h}$ (Fig. 2B and 2D). Electrolyte leakage analysis was performed on detached leaves from the non-acclimated plants. At $-3^{\circ} \mathrm{C}$, the percentages of electrolyte leakage were $41.4 \pm 4.6 \%$ for the vector control, $38.5 \pm 2.5 \%$ for the ICE1(WT)-overexpressing, and $28.2 \pm 2.2 \%$ for the ICE1(S403A)-overexpressing plants (Fig. 2E), indicating that the leaves of the ICE1(S403A)-overexpressing plants were less susceptible to freezing (Fig. 2E). These results demonstrate that the serine403 substitution to alanine enhanced freezing tolerance in Arabidopsis.

Overexpression of ICE1(WT) or ICE1(S403A) did not affect plant morphology (Fig. 3A, 3B), fresh weight (Fig. 3C), leaf area (Fig. 3D), or stomatal development (Fig. 4A) 
or density (Fig. 4B). SCREAM (SCRM)/ICE1 and SCREAM2 (SCRM2)/ICE2 are paralogous genes whose proteins interact with and regulate critical determinants of stomatal differentiation (Kanaoka et al., 2008). Interestingly, ICE1(WT) or ICE1(S403A) expression could suppress ice1-2 scrm-2 double mutant phenotypes of reduced stomatal density (not shown) and dwarfism (Fig. 3E; Kanaoka et al., 2008). ICE1(S403A) was functionally redundant to ICE1(WT).

\section{ICE1(S403A) overexpression enhanced induction of cold-regulated gene expression}

Because ICE1 controls the expression of $C B F 3 / D R E B 1 A$ and the regulon genes, such as COR47 and KIN1 (Chinnusamy et al., 2003), transcript abundance of these cold-regulated genes was monitored by quantitative RT-PCR analysis. CBF3/DREB1A transcript was greater in ICE1(WT)-overexpressing plants than in the vector control plants (Fig. 5), confirming results described previously (Chinnusamy et al., 2003; Miura et al., 2007a). ICE1(S403A) overexpression increased CBF3/DREB1A expression to a greater extent, which was most evident after $12 \mathrm{~h}$ of cold treatment (Fig. 5). Transgenic ICE1 and native ICE1 expression was also investigated in ICE1(WT) and ICE1(S403A) transgenic plants. Interestingly, native ICE1 expression was induced substantially by ICE1(WT) and, to greater extent, by ICE1(S403A) (Fig. 5), even prior to cold induction, probably because of the three canonical MYC cis-elements (CANNTG) present in $2 \mathrm{~kb}$ of the ICE1 promoter. Transgene ICE1 expression, which was driven by the cassava vein promoter, was similar in both ICE1(WT) and ICE1(S403A) (Fig. 5). Even though ICE1 transcript was accumulated under normal condition, induction of CBF3/DREB1A expression is required for cold treatment (Fig. 5), suggesting that ICE1 protein may be activated by cold and S403 is not a major residue for ICE1 activation. Transcript 
accumulation of CBF3/DREB1A regulon genes COR47 and KIN1, which are evident 12 $\mathrm{h}$ after exposure of the plants to low temperatures (Gilmour et al., 1998), was induced by overexpression of ICE1(WT) or ICE1(S403A) but to a greater extent by the later (Fig. 5). These results suggest that a prolonged expression of $C B F 3 / D R E B 1 A$ leads to higher levels of cold-regulated gene expression, probably resulting in the higher freezing tolerance of ICE1(S403A)-overexpressing plants.

Non-acclimated ICE1(WT) or ICE1(S403A) plants exhibited more tolerance to freezing stress (Figs. 2A, 2C). Low temperatures of $10^{\circ} \mathrm{C}$ or less induce CBF/DREB1 expression within $15 \mathrm{~min}$, and transcript accumulation increases with low temperature (Jaglo-Ottosen et al., 1998; Chinnusamy et al., 2003). In our conditions for freezing experiments, plants were kept at $4^{\circ} \mathrm{C}$ for $30 \min$ and $0^{\circ} \mathrm{C}$ for $1 \mathrm{~h}$, and then the temperature was successively decreased at $-1^{\circ} \mathrm{C} \mathrm{h}^{-1}$, as described in Experimental procedures. Therefore, it took $3.5 \mathrm{~h}$ to reach the desired temperature $\left(-3^{\circ} \mathrm{C}\right.$; Fig. $\left.2 \mathrm{~A}\right)$. Because we observed the expression of $C B F 3 / D R E B 1 A$ at $3 \mathrm{~h}$ of cold treatment to be up-regulated in ICE1(S403A) (Fig. 5), we suggest that the plants may have been partially acclimated to the cold. Thus, the ICE1(S403A) transgenic plants were able to survive better than the ICE1(WT) transgenic or wild-type plants at $-3^{\circ} \mathrm{C}$ (Fig. $2 \mathrm{~A}, 2 \mathrm{C}$ ).

\section{Serine 403 to alanine substitution increased stability of ICE1 against cold-induced proteasome degradation}

Low temperature induces ICE1 degradation after cold treatment through the ubiquitin/proteasome pathway, a process that is mediated by the ubiquitin E3 ligase HOS1 (Dong et al., 2006). To investigate whether the S403A substitution affects the 
stability of ICE1, ICE1 protein abundance was determined before and after cold treatment using western blot analysis. ICE1(WT) and ICE1(S403A) were expressed as T7-ICE1 fusion proteins, allowing for detection with anti-T7 tag antibody. Because the ice1-2 scrm-2 double mutation was complemented by T7-ICE1(WT) and T7-ICE1(S403A) (Fig. 3E), T7-tag did not disturb biological function of ICE1. A $24 \mathrm{~h}$ low temperature $\left(4^{\circ} \mathrm{C}\right)$ treatment results in substantial reduction in the T7-ICE1(WT) protein but affected T7-ICE1(S403A) protein abundance to a lesser degree (Fig. 6A). To confirm the stability of the ICE1(S403A) protein in vivo, we observed the fluorescence of GFP-ICE1 fusion proteins. The level of nuclear GFP-ICE1(WT) protein detected after cold treatment was reduced to a greater extent than GFP-ICE1(S403A) protein (Fig. 6B). These results indicate that the S403A substitution increases the stability of the ICE1 protein against cold-induced degradation.

\section{The substitution of serine 403 to alanine blocked the polyubiquitylation of ICE1 in} vivo

The proteasome inhibitor MG132 was used to assess whether low temperature-induced degradation of ICE1 proteins was due to ubiquitylation. High-molecular weight polypeptide bands corresponding to the polyubiquitylated forms of T7-ICE1 were detected in the immunoprecipitated T7-ICE1 proteins obtained from ICE1(WT)-overexpressing plants (Fig. 7A). However, the polyubiquitylated forms of T7-ICE1 were not detected in the immunoprecipitated T7-ICE1 proteins from ICE1(S403A)-overexpressing plants (Fig. 7A). These results suggest that the substitution of S403A inhibits the polyubiquitylation of ICE1 and, consequently, results in greater stability of the ICE1 protein against cold-induced degradation. 
Nonlysine residues such as serine, threonine, and cysteine are ubiquitylation sites in MHC-1 and the Bcl-2 family member Bid (Cadwell and Coscoy, 2005; Tait et al., 2007; Wang et al., 2007). Thus, an in vitro ubiquitylation assay of ICE1 proteins was assessed using HOS1 as an E3 ligase as described (Dong et al., 2006). After the addition of HOS1, a high molecular weight band was detected in both ICE1(WT) and ICE1(S403A) recombinant proteins (Fig. 7B), a pattern that is similar to another report (Dong et al., 2006). Thus, serine 403 is not the main target residue for ubiquitylation, but it inhibits the polyubiquitylation of ICE1 in vivo.

The effect of the S403A substitution on the ICE1 sumoylation status was determined. T7-ICE1(WT) or T7-ICE1(S403A) was transiently expressed in Nicotiana benthamiana leaves (Voinnet et al., 2003) and immunoprecipitated with anti-T7 antibody. Immunoblot analysis was then performed using anti-SUMO1 antibodies (Supplemental Fig. S3; Miura and Ohta, 2010). No significant difference was apparent, suggesting that sumoylation is not involved in regulation of ICE1 through S403. 


\section{Discussion}

S403A substitution in ICE1 enhanced GAL4-mediated transactivation in Arabidopsis protoplasts (Fig. 1C), and expression of cold-regulated genes, such as CBF3/DREB1A, COR47, and KIN1 in plants (Fig. 3), and cold tolerance (Fig. 2). Furthermore, the ICE1(S403A) protein level did not undergo cold-induced polyubiquitylation mediated by the ubiquitin E3 ligase HOS1 or proteasome degradation in vivo to the extent of ICE1(WT) (Figs. 6, 7), but ICE1(S403A) can be polyubiquitylated in vitro (Fig. 7B), suggesting that ICE1(S403A) facilitates protein stability in vivo even though S403 is not a major site of ubiquitin conjugation. Greater ICE1 stability caused by the S403A allele likely enhances expression of $C B F 3 / D R E B 1 A$ and its regulon genes such as COR47 and KIN1 (Fig. 5).

\section{Regulation of ICE1 transactivational activity}

Substitution of S403A in ICE1 enhanced the GAL4-mediated transactivation in Arabidopsis protoplasts (Fig. 1C), indicating the region around S403 has a role in the negative regulation of the transcriptional activity of ICE1. S403A substitution appears to repress this negative synergy. MYB15, a negative regulation of $C B F$ expression, binds to the $\mathrm{C}$ terminus of ICE1 (amino acids 395 to 494) and it is possible that MYB15 interaction can tranrepress ICE1 transcriptional activity (Agarwal et al., 2006). It is feasible that the transcriptional repression of $C B F 3 / D R E B 1 A$ expression by MYB15 is suppressed to some extent by S403A mutation. In this scenario, the S403A mutation may inhibit the association of MYB15 with ICE1, thereby allowing for the ICE1-activated transcription of $C B F 3 / D R E B 1 A$ in response to cold. 
The expression of $C B F 3 / D R E B 1 A$ was not expressed before cold treatment, as previously described (Chinnusamy et al., 2003; Miura et al., 2007), even though ICE1(WT) or ICE1(S403A) was overexpressed (Fig. 5). These results support the notion that low temperature is required for ICE1 transcriptional activation of CBF3/DREB1A in vivo, although the mechanism remains unelucidated.

\section{ICE1 stability caused by the S403 allele}

ICE1(S403A) was substantially more stable than ICE1(WT) to low-temperature-induced proteasomal degradation (Fig. 6). It is postulated that greater ICE1 abundance is responsible for the more pronounced and sustained induction of CBF3/DREB1A expression, which was most evident $12 \mathrm{~h}$ after cold treatment, a time when the $C B F 3 / D R E B 1 A$ transcript abundance had decreased substantially in vector control plants (Fig. 5). ICE1(S403A) protein abundance was increased after low temperature treatment, because cold causes the ubiquitylation of ICE1 protein by a RING finger ubiquitin E3 ligase HOS1 that leads to proteasomal degradation of the transcription factor (Dong et al., 2006). The expression of CBF3/DREB1A in the hos1 mutant was enhanced and therefore the ICE1 level was higher after cold treatment (Lee et al., 2001), as in the ICE1(S403A)-overexpressing plants (Fig. 5). S403A substitution apparently attenuates HOS1-mediated ubiquitylation and proteasomal degradation that is induced by low temperature (Fig. 7A). However, S403 is not principal ubiquitylation site for HOS1 but regulates the activity of the E3 ligase to ubiquitylate ICE1 (Fig. 7B).

The T7-ICE1(WT) polypeptide was the same molecular weight as the 
T7-ICE1(S403A) polypeptide (Fig. 6), and there was no additional band at a higher molecular weight, which may have corresponded to phosphorylated T7-ICE1, in either WT or S403A (Fig. 6). Furthermore, the substitution of S403 to aspartate (S403D) in ICE1 also increased the transactivational activity, as did the ICE1(S403A) substitution (Supplemental Fig. S1). These results suggest that S403 is not a major phosphorylation site.

Hydroxyl-oxygen side chains in serine and threonine residues may be subjected to $O$-linked glycosylation. An increased number of proline residues is present near the O-glycosylated serine or threonine residues, in comparison with nonglycosylated serines or threonines (Christlet and Veluraja, 2001). Because serine 403 in ICE1 is also in close proximity to proline residues (Fig. 1A), it is plausible that $O$-glycosylation occurs via S403. Because the recombinant ICE1 protein, expressed in E.coli, would not have had any glycosylation, the substitution of S403 may not have affected ubiquitylation (Fig. 7B). However, ICE1(S403A) may have blocked glycosylation in vivo, resulting in a different poly-ubiquitylation pattern (Fig. 7A). Among several $O$-linked glycosylations, such as $O$ - $N$-acetylgalactosamine and $O$-mannose, $\mathrm{O}-\mathrm{N}$-acetylglucosamine $(\mathrm{O}-\mathrm{GlcNAc})$ modification is an important posttranslational modification that modulates the function of many nuclear and cytoplasmic proteins, regulation of protein-protein interaction, competition with phosphorylation, nucleo-cytoplasmic shuttling, and modulation of transcription factor activity (Hu et al., 2010; Özcan et al., 2010). Because increasing O-GlcNAc levels enhances ubiquitylation and the RNAi of O-GlcNAc transferase reduced ubiquitylation (Guinez et al., 2008), O-GlcNAC and ubiquitylation may be linked. It is possible that the glycosylation of 
ICE1 at S403 regulates ubiquitylation and cold signaling.

\section{Neither ICE1(WT) nor ICE1(S403A) overexpression affect stomatal development}

ICE1/SCREAM has also been shown to be involved in stomatal differentiation (Kanaoka et al., 2008). This indicates that ICE1 links the transcriptional regulation of environmental adaptation and development in plants and that the mechanisms of transcriptional regulation by ICE1 might overlap between cold adaptation and stomatal development processes. However, there were no significant differences in either stomatal development or number among wild-type, ICE1(WT)-overexpressing and ICE1(S403A)-overexpressing plants (Fig. 4). The hypothesis is that ICE1 may act as an integrator of cold signaling and stomatal development. Normally, MYC-type transcription factors form dimers for transactivation. For example, mammalian Myc/Max/Mad can form dimers in multiple combinations through interactions mediated by their helix-loop-helix leucine zipper dimerization interfaces (Davis and Halazonetis, 1993; Ferré-D’Amaré et al., 1993; Luscher and Larsson, 1999). However, different members of the Myc/Max/Mad family have distinct biological functions. As described (Kanaoka et al., 2008), ICE1/SCRM can interact with three closely related bHLH transcription factors, SPCH, MUTA, and FAMA, for stomatal development, the entry into the stomatal cell lineage, the transition from meristemoid to guard mother cells, and the terminal differentiation of guard cells (Ohashi-Ito and Bergmann, 2006; MacAlister et al., 2007; Pillitteri et al., 2007). It is assumed that ICE1/SCRM and other MYC-type proteins, as well as SPCH, MUTA, and FAMA, can form several combinations to control cold signaling or stomatal development. The stabilization of ICE1 conferred by the S403A substitution did not affect the stomatal development (Fig. 4), suggesting that 
the cold-induced degradation of ICE1 mediated by HOS1 is specific to cold adaptation but not to stomatal development.

The overexpression of ICE2 also conferred a freezing tolerance in Arabidopsis (Fursova et al., 2009). Expression of ICE2/SCRM2(R203H), which corresponds to the ice1 mutation $(\mathrm{R} 236 \mathrm{H})$, phenocopied the constitutive stomatal differentiation of ice1/scrm in the epidermis (Kanaoka et al., 2008). These results demonstrate that ICE2/SCRM2 is functionally related to ICE1 and that ICE2/SCRM2 may exert a similar mechanism of transcriptional regulation as ICE1. The amino acid sequence surrounding S403 in ICE1 is highly conserved in ICE2/SCRM2 (Supplemental Fig. S4). It is possible that S359 of ICE2, which is corresponds to S403 of ICE1, is likely to be involved in a similar mechanism as the S403 residue of ICE1.

The overexpression of $C B F / D R E B 1 s$ improves the freezing tolerance of plants but results in severe growth retardation under normal conditions (Jaglo-Ottosen et al., 1998; Kasuga et al., 1999; Gilmour et al. 2004). ICE1(S403A)-overexpressing plants were also more tolerant to freezing temperatures, but they grew similar to WT plants under normal conditions, even though the expression of ICE1(S403A) was driven by a constitutive cassava vein mosaic virus promoter (Fig. 3). ICE1 homologs have also been identified in barley and wheat (Skinner et al., 2006; Tondelli et al., 2006; Badawi et al., 2008). The overexpression of ICE1(S403A) can provide a potent strategy for improving the freezing tolerance of crop plants, thereby increasing their productivities and potentially expanding their global distribution. 


\section{Experimental procedures}

\section{Transient expression assay}

Arabidopsis protoplasts were prepared from two-week-old wild-type seedlings with the Cellulase Ononzuka R-10 and Macerozyme R-10 (Yakult Pharmaceutical, http://www.yakult.co.jp/ypi/en/index.html), as described (Tiwari et al., 2003; Yoo et al., 2007). Plasmid DNA of a reporter GAL4-GUS (Tiwari et al., 2003) and an effector GAL4DB-ICE1(WT) or its variants was introduced into Arabidopsis protoplasts by polyethylene glycol-mediated transfection (Tiwari et al., 2003; Yoo et al., 2007). For each transfection, $5 \mu \mathrm{g}$ of the reporter and $4 \mu \mathrm{g}$ of the effector plasmid DNA were used. After transfection, the protoplasts were incubated at $23^{\circ} \mathrm{C}$ in dark for $48 \mathrm{~h}$. One $\mu \mathrm{g}$ of the reference plasmid DNA, 35S-LUC, was used to normalize the efficiency of each transfection. GUS activity was measured as described (Yoo et al., 2007). A luciferase assay was performed with the Luciferase Reporter Assay system (Promega, http://www.promega.com) using a luminescence reader (Gene Light 55, Microtech Nichion, http://nition.com/en/).

\section{Plant freezing assay}

The whole plant freezing assay was performed essentially as described, with slight modifications (Miura et al., 2007a; Miura and Ohta, 2010). Wild-type (Col-0), vector control (\#8), ICE1(WT)-overexpressing (\#12), and ICE1(S403A)-overexpressing plants (in this study) were grown at $23^{\circ} \mathrm{C}$ for 3 weeks under constant illumination in soil. For cold acclimation, 3-week-old plants were incubated at $4^{\circ} \mathrm{C}$ for $7 \mathrm{~d}$. Non-acclimated plants were incubated at $4^{\circ} \mathrm{C}$ for $30 \mathrm{~min}$ and then at $0^{\circ} \mathrm{C}$ for $1 \mathrm{~h}$. Next, the temperature was successively decreased $1{ }^{\circ} \mathrm{C}$ per hour until $-4^{\circ} \mathrm{C}$ and held at $-4^{\circ} \mathrm{C}$ for $4 \mathrm{hr}$ in a 
programmed incubator (IN602, Yamato, http://www.yamatokikai.com). Cold-acclimated plants were incubated at $0^{\circ} \mathrm{C}$ for $1 \mathrm{~h}$, and the temperature was successively decreased $2^{\circ} \mathrm{C}$ per hour until $-8^{\circ} \mathrm{C}$ and held at $-8^{\circ} \mathrm{C}$ for $4 \mathrm{hr}$ in a programmed incubator. To facilitate uniform nucleation, crushed ice was spread over the plants at $0^{\circ} \mathrm{C}$. After cold acclimation, the plants were kept overnight at $4{ }^{\circ} \mathrm{C}$ and then transferred to $23^{\circ} \mathrm{C}$. The survival ratio was determined one week after the freezing treatment.

\section{RNA preparation and quantitative RT-PCR}

Vector control (\#8), ICE1(WT)-overexpressing (\#12) (Miura et al., 2007a), and ICE1(S403A)-overexpressing (\#13) plants (in this study) were grown on half-MS agar plates at $23^{\circ} \mathrm{C}$ for 10 days under a long-day photoperiod $(16 \mathrm{~h} \mathrm{light} / 8 \mathrm{~h}$ dark). The plants were then subjected to cold treatments at $4^{\circ} \mathrm{C}$. Isolation of the total RNA, cDNA synthesis, and quantitative RT-PCR was performed as described (Miura et al., 2009). Primers used for the real-time PCR are listed in Supplemental Table S1.

\section{Construction of plasmids}

Mutations in the ICE1 coding regions were introduced by PCR-based methods using the PrimeSTAR DNA polymerase (Takara Bio, http://www.takara-bio.com) and pairs of primers (Supplemental Table S2). The mutated ICE1 coding regions were amplified by the PrimeSTAR DNA polymerase with ICE1-GDF and ICE1-HAR primers and then digested with XmaI and XhoI. The digested PCR products were introduced into the plant expression vector 35S-GAL4 DB digested with XmaI and SalI (Ohta et al., 2000) to produce 35S-GAL4-ICE1(mutant) fusion genes. To construct pCsV-T7-ICE1(S403A), the ICE1(S403A) coding region was amplified by the 
PrimeSTAR DNA polymerase (Takara Bio) with ICE1-expF and ICE1-EGR primers (Supplemental Table S2), and the PCR product was introduced into pCsV1300-T7 as described (Miura et al., 2007a; Verdaguer et al., 1996).

The ICE1 or ICE1(S403A) coding region was amplified by the PrimeSTAR DNA polymerase with primers, ICE1-expF and ICE1-HAR, and then digested with BamHI and SalI. The digested PCR product was cloned into an E.coli expression vector, pCold ProS2 (Takara Bio). The resulting plasmids were named as pCold-ICE1 and pCold-ICE1(S403A). Each plasmid was transformed into E.coli Origami 2(DE3) pLysS cells (Novagen, http://www.emdchemicals.com/life-science-research).

\section{Plant transformation}

pCsV-ICE1(S403A) was transformed into wild-type Arabidopsis plants (Col-0 background) by Agrobacterium-mediated transformation (Miura et al., 2007a; Miura et al., 2009). Hygromycin-resistant plants were selected, and semi-quantitative RT-PCR was carried out with the primers ICE1S403AF and NOS-transR (Supplemental Table S2) to check the expression levels of the transgenes (Supplemental Fig. S2).

\section{Agroinfiltration procedure}

Agroinfiltration assay was performed as described (Voinnet et al., 2003). Briefly, Agrobacterium tumefaciens strain GV3101 containing pCsV-T7-ICE1(WT), pCsV-T7-ICE1(S403A), or p19 (Voinnet et al., 2003) was grown at $28^{\circ} \mathrm{C}$ in L-broth supplemented with $10 \mathrm{mM}$ MES, $20 \mu \mathrm{M}$ acetosyringone, $50 \mu \mathrm{g} \mathrm{ml}^{-1}$ kanamycin, $30 \mu \mathrm{g}$ $\mathrm{ml}^{-1}$ gentamycin, and $30 \mu \mathrm{g} \mathrm{ml}^{-1}$ rifampicin to stationary phase. Bacteria were sedimented by centrifugation at $5,000 \mathrm{~g}$ for $15 \mathrm{~min}$ at room temperature, suspended in 
$10 \mathrm{mM} \mathrm{MgCl}_{2}, 10 \mathrm{mM}$ MES and $100 \mu \mathrm{M}$ acetosyringone, and left for more than $3 \mathrm{~h}$. Equal volume of bacteria containing pCsV-T7-ICE1(WT) or pCsV-T7-ICE1(S403A) and p19 was mixed. The mixture was infiltrated into the abaxial sides of 3-4-week-old Nicotiana benthamiana leaves. After 3-4 days incubation, plants were ground in extraction buffer as described (Murtas et al., 2003).

\section{Western blot analysis and Immunoprecipitation}

Ten day-old seedlings of ICE1(WT)-overexpressing (\#12) and ICE1(S403A)-overexpressing (\#13) plants were ground in extraction buffer, as described (Murtas et al., 2003). Total protein (20-40 $\mu \mathrm{g})$ was separated by SDS-PAGE, and western blot analysis was performed as described (Miura et al., 2005; Miura et al., 2009).

To detect ubiquitylated ICE1, ten-day-old ICE1(WT)-overexpressing (\#12) and ICE1(S403A)-overexpressing (\#13) plants were pretreated with $50 \mu \mathrm{M}$ proteasome inhibitor (MG132) for $24 \mathrm{~h}$ and then treated at $4^{\circ} \mathrm{C}$ for $15 \mathrm{~h}$. Total protein extract $(10 \mathrm{mg}$ protein) was immunoprecipitated with $\mathrm{T} 7$ antibodies coupled to agarose beads (Novagen) for $4 \mathrm{~h}$ at $4^{\circ} \mathrm{C}$, and the beads were recovered by centrifugation, washed 5 times with the extraction buffer, and eluted according to the manufacturer's instructions. The eluted samples were separated by SDS-PAGE and immunoblot analysis with monoclonal antibody against ubiquitin (P4D1, Santa Cruz Biotechnology Inc, http://www.scbt.com) was performed.

\section{Ubiquitylation assay}

The ICE1 or ICE1(S403A) coding region was cloned into pCold ProS2 (Takara Bio). 
When the E.coli cells grew to mid-log phase, IPTG was added to the medium at a final concentration of $0.4 \mu \mathrm{M}$. The culture was incubated at $15^{\circ} \mathrm{C}$ for $24 \mathrm{~h}$. The bacterial cell walls were disrupted by the BugBuster Protein Extraction Reagent with rLysozyme and Benzonase Nuclease (Novagen). The recombinant proteins, His-ProS2-ICE1(WT) and His-ProS2-ICE1(S403A), were purified with the HIS-Select Nickel Affinity Gel (Sigma, http://www.sigmaaldrich.com), according to the manufacturer's instructions. MBP-HOS1 (Dong et al., 2006) was purified using amylase resin (New England Biolabs, http://www.neb.com), as instructed. The ubiquitylation assay was performed using the Ubiquitylation Kit (Enzo Life Sciences, http://www.enzolifesciences.com) with $\mathrm{UbcH} 5 \mathrm{~b}$ for E2, according to the instructions.

\section{Microscopic observation}

The coding region of ICE1(S403A) was excised from the pCsV-ICE1(S403A) plasmid DNA by digestion with BamHI. The resulting DNA fragment was introduced into the BamHI site of the binary vector pEGAD to generate GFP-ICE1(S403A). The direction of the insert was confirmed by sequencing, and the plasmid DNA with a sense insert orientation was used for further experiments. This GFP-ICE1(S403A) plasmid was introduced into Agrobacterium strain GV3101 and transformed into wild-type Arabidopsis plants (Col-0). T2 transgenic lines resistant to Basta (glufosinate) were chosen for the analysis of GFP expression. Fluorescence of the GFP-ICE fusion proteins was observed with a confocal laser-scanning microscope (TCS SP2, Leica, http://www.leica.com). 


\section{Acknowledgments}

We thank Dr. Jian-Kang Zhu and Dr. Keiko Torii for providing GFP-ICE1 transgenic plants, MBP-HOS1 plasmids, and the ice1-2 scrm-2 mutant. We also thank members of the Miura Lab for their critical comments on the manuscript. This work was supported in part by grants from the Special Coordination Funds for Promoting Science and Technology from the Japanese Ministry of Education, Culture, Sports, Science and Technology; from a Grant-in-Aid for Young Scientists (B, no. 21770032); and by the U.S. Department of Agriculture-National Research Initiative Competitive Grants Program (no. 2008-35100-04529). 


\section{References}

Agarwal M., Hao Y., Kapoor A., Dong C.H., Fujii H., Zheng X. and Zhu J.K. (2006) A R2R3 type MYB transcription factor is involved in the cold regulation of CBF genes and in acquired freezing tolerance. J. Biol. Chem. 281, 37636-37645.

\section{Badawi M., Reddy Y.V., Agharbaoui Z., Tominaga Y., Danyluk J., Sarhan F. and} Houde M. (2008) Structure and functional analysis of wheat ICE (inducer of CBF expression) genes. Plant Cell Physiol. 49, 1237-1249.

Baker S.S., Wilhelm K.S. and Thomashow M.F. (1994) The 5'-region of Arabidopsis thaliana cor15a has cis-acting elements that confer cold-, drought- and ABA-regulated gene expression. Plant Mol. Biol. 24, 701-713.

Cadwell K. and Coscoy L. (2005) Ubiquitination on nonlysine residues by a viral E3 ubiquitin ligase. Science, 309, 127-130.

Chinnusamy V., Ohta M., Kanrar S., Lee B.H., Hong X., Agarwal M. and Zhu J.K. (2003) ICE1: a regulator of cold-induced transcriptome and freezing tolerance in Arabidopsis. Genes Dev. 17, 1043-1054.

Chinnusamy V., Zhu J. and Zhu J.K. (2007) Cold stress regulation of gene expression in plants. Trends Plant Sci. 12, 444-451.

Christlet T.H.T. and Veluraja K. (2001) Database analysis of $O$-glycosylation sites in proteins. Biophys. J. 80, 952-960.

Davis L.J. and Halazonetis T.D. (1993) Both the helix-loop-helix and the leucine zipper motifs of c-Myc contribute to its dimerization specificity with Max. Oncogene, 8, 125-132.

Dong C.H., Agarwal M., Zhang Y., Xie Q. and Zhu J.K. (2006) The negative regulator of plant cold responses, HOS1, is a RING E3 ligase that mediates the 
ubiquitination and degradation of ICE1. Proc. Natl. Acad. Sci. USA, 103, 8281-8286.

Ferré-D’Amaré A.R., Prendergast G.C., Ziff E.B. and Burley S.K. (1993)

Recognition by Max of its cognate DNA through a dimeric b/HLH/Z domain.

Nature, 363, 38-45.

Fowler S. and Thomashow M.F. (2002) Arabidopsis transcriptome profiling indicates that multiple regulatory pathways are activated during cold acclimation in addition to the CBF cold response pathway. Plant Cell, 14, 1675-1690.

Fursova O.V., Pogorelko G.V. and Tarasov V.A. (2009) Identification of ICE2, a gene involved in cold acclimation which determines freezing tolerance in Arabidopsis thaliana. Gene, 429, 98-103.

Gilmour, S.J., Zarka, D.G., Stockinger, E,J,, Salazar, M.P., Houghton, J.M. and Thomashow, M.F. (1998) Low temperature regulation of the Arabidopsis CBF family of AP2 transcriptional activators as an early step in cold-induced COR gene expression. Plant J. 16, 433-442

Gilmour S.J., Fowler S.G. and Thomashow M.F. (2004) Arabidopsis transcriptional activators $\mathrm{CBF} 1, \mathrm{CBF} 2$, and $\mathrm{CBF} 3$ have matching functional activities. Plant Mol. Biol. 54, 767-781.

Guinez C., Mir A-M, Dehennaut V., Cacan R., Harduin-Lepers A., Michalski J-C. and Lefebvre T. (2008) Protein ubiquitination is modulated by $O$-GlcNAc glycosylation. FASEB J. 22, 2901-2911.

Guy, C.L. (1990) Cold acclimation and freezing stress tolerance: Role of protein metabolism. Annu. Rev. Physiol. Plant Mol. Biol. 41, 187-223.

Hu P., Shimoji S. and Hart G.W. (2010) Site-specific interplay between 
O-GlcNAcylation and phosphorylation in cellular regulation. FEBS Lett. 584, $2526-2538$.

Ishitani, M., Xiong, L., Lee, H., Stevenson, B. and Zhu, J.K. (1998) HOS1, a genetic locus involved in cold-responsive gene expression in Arabidopsis. Plant Cell, 10, $1151-1161$.

Jaglo-Ottosen K.R., Gilmour S.J., Zarka D.G., Schabenberger O. and Thomashow M.F. (1998) Arabidopsis CBF1 overexpression induces COR genes and enhances freezing tolerance. Science, 280, 104-106.

Kanaoka M.M., Pillittere L.J., Fujii H., Yoshida Y., Bogenschutz N.L., Takabayashi J., Zhu J.K. and Torii K.U. (2008) SCREAM/ICE1 and SCREAM2 specify three cell-state transitional steps leading to Arabidopsis stomatal differentiation. Plant Cell, 20, 1775-1785.

Kasuga M., Liu Q., Miura S., Yamaguchi-Shinozaki K. and Shinozaki K. (1999) Improving plant drought, salt, and freezing tolerance by gene transfer of a single stress-inducible transcription factor. Nat. Biotechnol. 17, 287-291.

Kreps J.A., Wu Y., Chang H.S., Zhu T., Wang X. and Harper J. F. (2002) Transcriptome changes for Arabidopsis in response to salt, osmotic, and cold stress. Plant Physiol. 130, 2129-2141.

Lee B.H., Henderson D.A. and Zhu J.K. 2005. The Arabidopsis cold-responsive transcriptome and its regulation by ICE1. Plant Cell, 17, 3155-3175.

Lee H., Xiong L., Gong Z., Ishitani M., Stevenson B. and Zhu J.K. (2001) The Arabidopsis HOS1 gene negatively regulates cold signal transduction and encodes a RING finger protein that displays cold-regulated nucleo-cytoplasmic partitioning. Genes Dev. 15, 912-924. 
Lissarre, M., Ohta, M., Sato, A. and Miura, K. (2010) Cold-responsive gene regulation during cold acclimation in plants. Plant signal. Behav. 5, 948-952.

Liu Q., Kasuga M., Sakuma Y., Abe H., Miura S., Yamaguchi-Shinozaki K. and Shinozaki K. (1998) Two transcription factors, DREB1 and DREB2, with an EREBP/AP2 DNA binding domain separate two cellular signal transduction pathways in drought- and low-temperature-responsive gene expression, respectively, in Arabidopsis. Plant Cell, 10, 1391-1406.

Luscher B. and Larsson L.G. (1999) The basic region/helix-loop-helix/leucine zipper domain of Myc proto-oncoproteins: function and regulation. Oncogene, 18, 2955-2966.

MacAlister C.A., Ohashi-Ito K. and Bergmann D.C. (2007) Transcription factor control of asymmetric cell divisions that establish the stomatal lineage. Nature, $\mathbf{4 4 5}$, $537-540$

Miura K. and Hasegawa P.M. (2010) Sumoylation and other ubiquitin-like post-translational modifications in plants. Trends Cell Biol. 20, 223-232.

Miura K., Jin J.B., Lee J., Yoo C.Y., Stirm V., Miura T., Ashworth E.N., Bressan R.A., Yun D.J. and Hasegawa P.M. (2007a) SIZ1-mediated sumoylation of ICE1 controls CBF3/DREB1A expression and freezing tolerance in Arabidopsis. Plant Cell, 19, 1403-1414.

Miura K., Jin J.B. and Hasegawa P.M. (2007b) Sumoylation, a post-translational regulatory process in plants. Curr. Opin. Plant Biol. 10, 495-502.

Miura K., Lee J., Jin J.B., Yoo C.Y., Miura T. and Hasegawa P.M. (2009) Sumoylation of ABI5 by the Arabidopsis SUMO E3 ligase SIZ1 negatively regulates abscisic acid signaling. Proc. Natl. Acad. Sci. USA, 106, 5418-5423. 
Miura K. and Ohta M. (2010) SIZ1, a small ubiquitin-related modifier ligase, controls cold signaling through regulation of salicylic acid accumulation. J. Plant. Physiol. 167, 555-560.

Miura K., Rus A., Sharkhuu A. et al. (2005) The Arabidopsis SUMO E3 ligase SIZ1 controls phosphate deficiency responses. Proc. Natl. Acad. Sci. USA, 102, $7760-7765$.

Mohideen F., Capili A.D., Bilimoria P.M., Yamada T., Bonni A. and Lima C.D. (2009) A molecular basis for phosphorylation-dependent SUMO conjugation by the E2 UBC9. Nat. Struct. Mol. Biol. 16, 945-952.

Murtas G., Reeves P.H., Fu Y.F., Bancroft, Dean C. and Coupland G. (2003) A nuclear protease required for flowering-time regulation in Arabidopsis reduces the abundance of SMALL UBIQUITIN-RELATED MODIFIER conjugates. Plant Cell, 15, 2308-2319.

Ohashi-Ito K. and Bergmann D.C. (2006) Arabidopsis FAMA controls the final proliferation/differentiation switch during stomatal development. Plant Cell, 18, 2493-2505.

Ohta M., Ohme-Takagi M. and Shinshi H. (2000) Three ethylene-responsive transcription factors in tobacco with distinct transactivation functions. Plant J. 22, 29-38.

Özcan S., Andrali S.S. and Cantrell J.E.L. (2010) Modulation of transcription factor function by O-GlcNAc modification. Biochim. Biophys. Acta. 1799, 353-364.

Pillitteri L.J., Sloan D.B., Bogenschutz N.L. and Torii K.U. (2007) Termination of asymmetric cell division and differentiation of stomata. Nature, 445, 501-505.

Seki, M., Narusaka, M., Ishida, J. et al. (2002) Monitoring the expression profiles of 
7000 Arabidopsis genes under drought, cold and high-salinity stresses using a full-length cDNA microarray. Plant J. 31, 279-292.

Skinner J.S., Szucs P., von Zitzewitz J., Marquez-Cedillo L., Filichkin T., Stockinger E.J., Thomashow M.F., Chen T.H. and Hayes P.M. (2006) Mapping of barley homologs to genes that regulate low temperature tolerance in Arabidopsis. Theor. Appl. Genet. 112, 832-842.

Stockinger E.J., Gilmour S.J. and Thomashow M.F. (1997) Arabidopsis thaliana CBF1 encodes an AP2 domain-containing transcriptional activator that binds to the C-repeat/DRE, a cis-acting DNA regulatory element that stimulates transcription in response to low temperature and water deficit. Proc. Natl. Acad. Sci. USA, 94, 1035-1040.

Tait S.W.G., de Vries E., Maas C., Keller A.M., D'Santos C.S. and Borst J. (2007) Apoptosis induction by Bid requires unconventional ubiquitination and degradation of its N-terminal fragment. J. Cell. Biol. 179, 1453-1466.

Thomashow M.F. (1999) PLANT COLD ACCLIMATION: Freezing tolerance genes and regulatory mechanisms. Annu. Rev. Plant Physiol. Plant Mol. Biol. 50, 571-599.

Tiwari S.B., Hagen G. and Guilfoyle T. (2003) The roles of auxin response factor domains in auxin-responsive transcription. Plant Cell, 15, 533-543.

Tondelli, A., Francia, E., Barabaschi, D., Aprile, A., Skinner, J.S., Stockinger, E.J., Stanca, A.M. and Pecchioni, N. (2006) Mapping regulatory genes as candidates for cold and drought stress tolerance in barley. Theor. Appl. Genet. 112, 445-454.

Verdaguer B., de Kochko A., Beachy R.N. and Fauquet C. (1996) Isolation and expression in transgenic tobacco and rice plants, of the cassava vein mosaic virus 
(CVMV) promoter. Plant Mol. Biol. 31, 1129-1139.

Voinnet O., Rivas S., Mestre P. and Baulcombe D. (2003) An enhanced transient expression system in plants based on suppression of gene silencing by the p19 protein of tomato bushy stunt virus. Plant J. 33, 949-956.

Wang X., Herr R.A., Chua W.J., Lybarger L., Wiertz E.J. and Hansen T.H. (2007) Ubiquitination of serine, threonine, or lysine residues on the cytoplasmic tail can induce ERAD of MHC-I by viral E3 ligase mK3. J. Cell Biol. 177, 613-624.

Yamaguchi-Shinozaki K. and Shinozaki K. (1994) A novel cis-acting element in an Arabidopsis gene is involved in responsiveness to drought, low-temperature, or high-salt stress. Plant Cell, 6, 251-264.

Yoo S.D., Cho Y.H. and Sheen J. (2007) Arabidopsis mesophyll protoplasts: a versatile cell system for transient gene expression analysis. Nat. Protoc. 2, 1565-1572. 


\section{Short legends for Supporting Information}

Supplemental Table S1. Primers used for mutagenesis and construction.

Supplemental Table 2. Primers used for real-time PCR and RT-PCR analyses.

Supplemental Fig. S1. Identification of serine/threonine residues affecting the transactivation activity of ICE1.

Supplemental Fig. S2. ICE1(WT) or ICE1(S403A) expression in transgenic plants.

Supplemental Fig. S3. The sumoylation status of ICE1 was not altered by substitution of the serine 403 to alanine.

Supplemental Fig. S4. Sequence alignment of the flanking regions of K393 and S403 in ICE1 and the corresponding region in ICE2. 


\section{Figure legends}

Fig. 1. Substitution of serine 403 to alanine enhances the transactivation activity of

ICE1. (A) Amino acid sequence near the sumoylation site, K393. Serine or threonine residues substituted to alanine are underlined, and lysine 393 is boxed. (B) Schematic diagram of the reporter and effector plasmids used in the transient expression assay. Wild-type and mutated ICE1 open-reading frames were inserted into the effector plasmid fused with GAL4 DB, the DNA-binding domain of the yeast transcription factor, GAL4. GUS encodes $\beta$-glucuronidase, which is used as a reporter. NOS is the termination signal of the nopaline synthase gene. $\Omega$ is the translational enhancer of the tobacco mosaic virus. (C) Relative GUS activities after transfection with the reporter, GAL4-GUS, and the effector plasmid, 35S-GAL4-ICE1 or 35S-GAL4-ICE1(S403A). Firefly luciferase activity (35S-LUC) was used for normalization; GUS activity is expressed in arbitrary units relative to the activities of firefly luciferase. The values are averages of three independent experiments, and error bars indicate standard deviations (SD).

Fig. 2. ICE1(S403A) overexpression improved the freezing tolerance of non-acclimated and cold-acclimated plants. (A) Non-acclimated plants and (B) cold-acclimated plants were treated at $-4^{\circ} \mathrm{C}$ and $-8^{\circ} \mathrm{C}$, respectively. Photographs are of representative wild-type (a), vector control (b), ICE1-overexpressing [line \#12 (c)], and ICE1(S403A)-overexpressing plants [line \#5 (d), \#12 (e), and \#13 (f)]. (C)

Quantification of the survival rates for non-acclimated plants after a freezing treatment at $-4^{\circ} \mathrm{C}$ and (D) for cold-acclimated plants after a freezing treatment at $-8^{\circ} \mathrm{C}$. Data shown are mean values with standard error $(n=4)$. The tolerance of the 
ICE1(S403A)-overexpressing plants was significantly different from the wild-type and vector control plants (T test, $P<0.01$ ) and from the ICE1-overexpressing plants ( $\mathrm{T}$ test, $P<0.05$ ). (E) Electrolyte leakage at $-3^{\circ} \mathrm{C}$. The electrolyte leakage of the ICE1(S403A)-overexpressing plants was significantly lower than that of the vector control and ICE1-overexpressing plants (T test, $P<0.05$ ).

Fig. 3. Growth resulting from the overexpression of ICE1(WT) and ICE1(S403A). Photographs are representative of vector control, ICE1(WT), and ICE1(S403A) transgenic plants grown for 4 weeks (A) or 8 weeks (B). Fresh weight of 4 -week-old plants and leaf area of the fifth rosette leaf of 8-week-old plants were measured. (H) A representative photograph of a heterologous ice1-2/+ scrm-2 and ice1-2/- scrm-2 double mutant and an ice1-2/- scrm-2 double mutant harboring ICE1(WT) and ICE1(S403A). Bars $=1 \mathrm{~cm}(\mathrm{~A})$, or $5 \mathrm{~cm}(\mathrm{~B})$.

Fig. 4. Stomatal development of ICE1(WT) and ICE1(S403A)-overexpressing plants. A. Abaxial leaf epidermis of WT (a), ICE1(WT) (b) and ICE1(S403A) (c)-overexpressing plants. Bar indicates 20- $\mu \mathrm{m}$ length. B. Mean number of stomata on the abaxial leaf epidermis. Mean $\pm \operatorname{SE}(n=16)$.

Fig. 5. Induction of cold regulated genes is enhanced by the overexpression of ICE1(S403A).

Relative mRNA transcript levels of transgenic ICE1, endogenous ICE1, CBF3/DREB1A, COR47, and KIN1 in vector control (\#8), ICE1-overexpressing (\#12) and ICE1(S403A)-overexpressing (\#13) seedlings were determined by quantitative RT-PCR 
analyses. Ten-day-old seedlings grown at $23^{\circ} \mathrm{C}$ were incubated at $4{ }^{\circ} \mathrm{C}$ for the indicated time. Data are means with SD $(n=3)$ from a representative experiment of three independent experiments.

Fig. 6. The S403A substitution stabilizes ICE1 against cold-induced degradation. (A) Detection of the T7-ICE1 protein by western blot analysis. Fourteen-day-old ICE1(WT)- and ICE1(S403A)-overexpressing plants were examined before $(0 \mathrm{~h})$ or after (24 h) treatment at $4^{\circ} \mathrm{C}$ for $24 \mathrm{~h}$. The T7-ICE1 protein was detected with anti-T7 antiserum. Histone H3 was detected as a loading control. (B) Visualization of GFP-ICE1 fusion proteins. Ten-day-old seedlings of GFP-ICE1(WT) and GFP-ICE1(S403A) transgenic plants grown on agar plates were treated $\left(4^{\circ} \mathrm{C}\right.$ for $\left.24 \mathrm{~h}\right)$ or not treated $\left(23^{\circ} \mathrm{C}\right)$ with cold stress. Roots of the seedlings were observed immediately after cold stress under a confocal microscope. Scale bars $=150 \mu \mathrm{m}$.

Fig. 7. The S403A substitution inhibits the polyubiquitylation of ICE1 in vivo. (A) Polyubiquitylation status in vivo. Ten-day-old ICE1(WT)- and ICE1(S403A)-overexpressing plants were treated with the proteasome inhibitor MG132 $(50 \mu \mathrm{M})$ for $24 \mathrm{~h}$ and then subjected to cold treatment at $4^{\circ} \mathrm{C}$ for $15 \mathrm{~h}$. Total protein extract (10 mg protein) was immunoprecipitated with $\mathrm{T} 7$ antibodies coupled to agarose beads and analyzed by immunoblotting with antibody against ubiquitin (upper panel). The lower panel indicates the immunoblot analysis of the input total protein extract with T7 antibody as a loading control. (B) In vitro ubiquitylation assay.

His-ProS2-ICE1(WT), His-ProS2-ICE1(S403A), and MBP-HOS1 recombinant proteins were prepared. Without HOS1, the ubiquitylation of ICE1 was not detected even 
though ubiquitin, E1, and E2 proteins were added. Addition of HOS1 enhanced the ubiquitylation of both ICE1(WT) and ICE1(S403A). The blot was incubated with anti-ProS2 antibody to detect His-ProS2-ICE1(WT) or His-ProS2-ICE1(S403A). The arrowhead indicates polyubiquitylated ICE1(WT) and ICE1(S403A). 


$$
\begin{aligned}
& \text { A } \begin{array}{cccc}
387389 & 393 & 399400 & 403 \\
\text { T P Q T L S C R V K E E L C P S S L P S P }
\end{array} \\
& \text { sumoylation }
\end{aligned}
$$
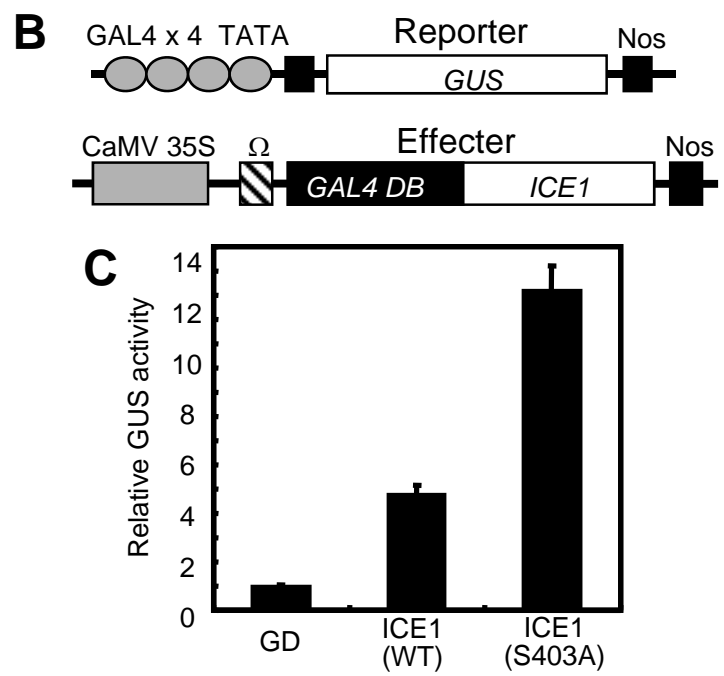

Figure 1 

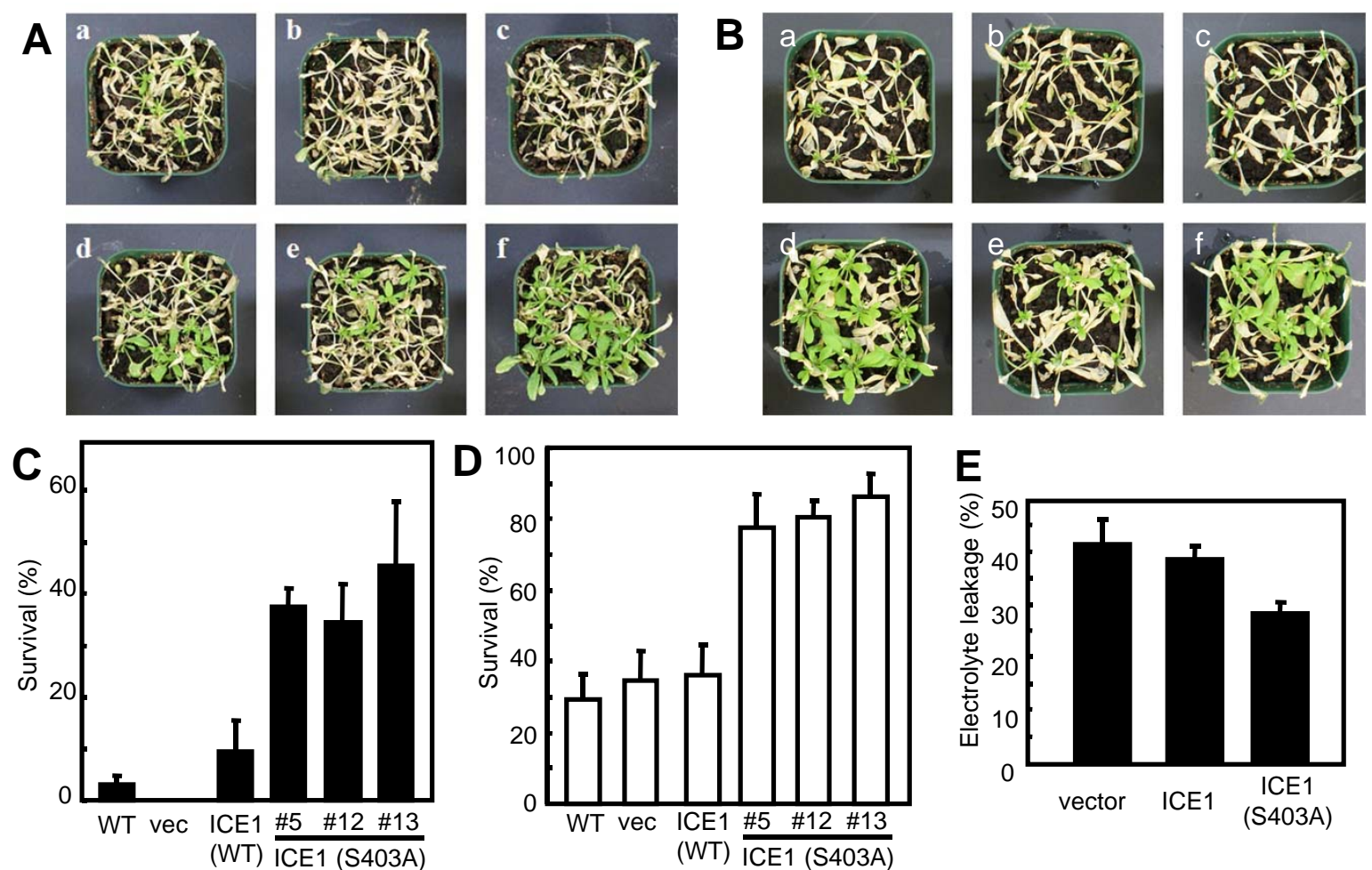

Figure 2 

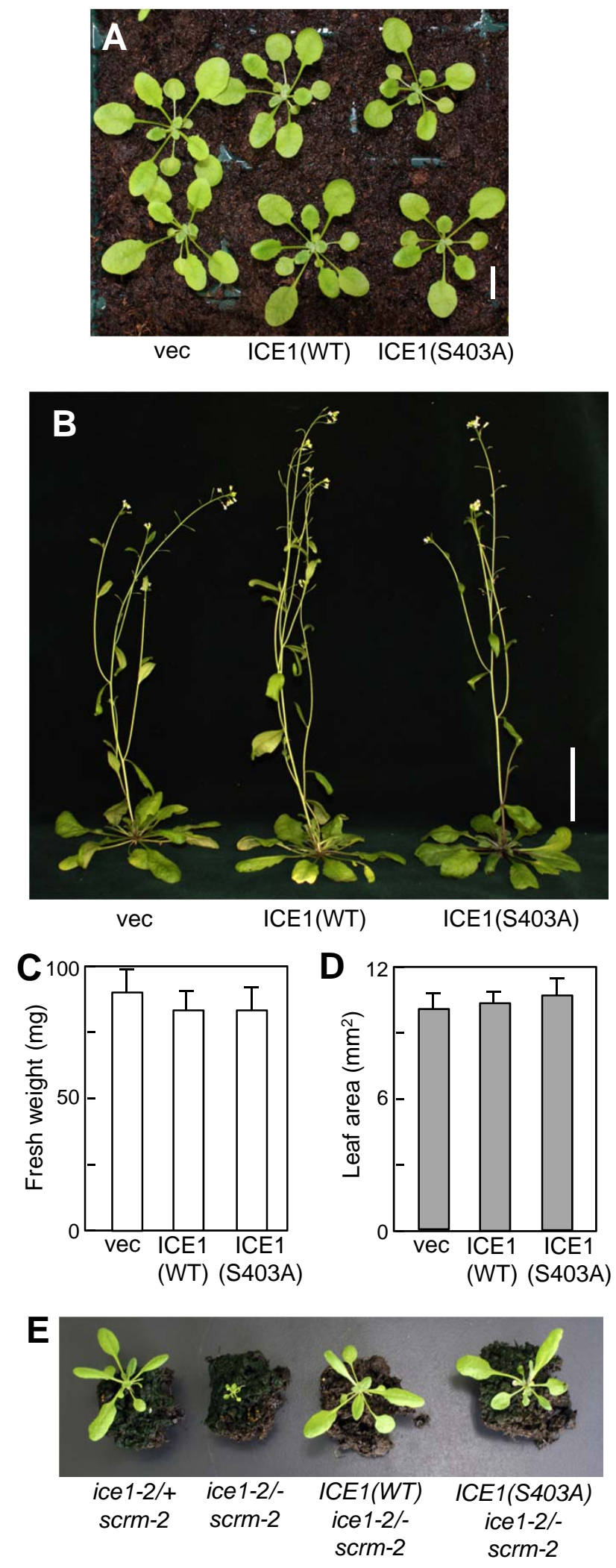

Figure 3 

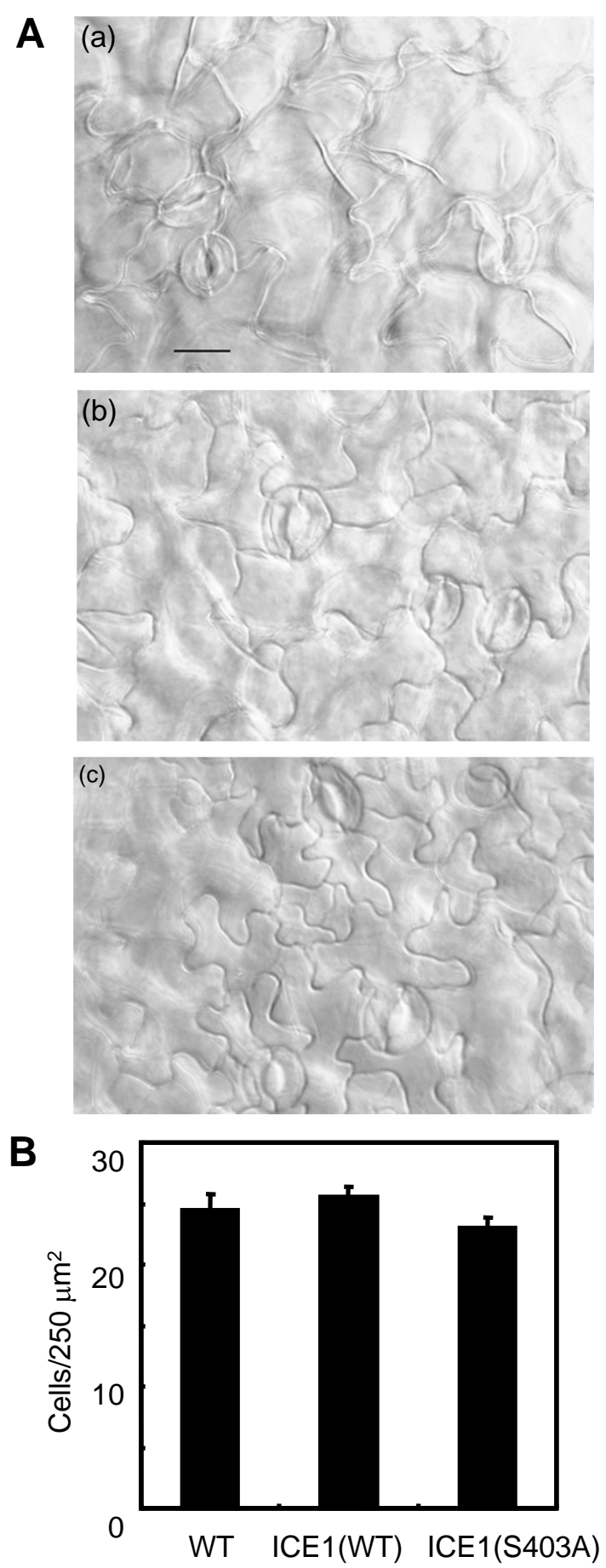

Figure 4 

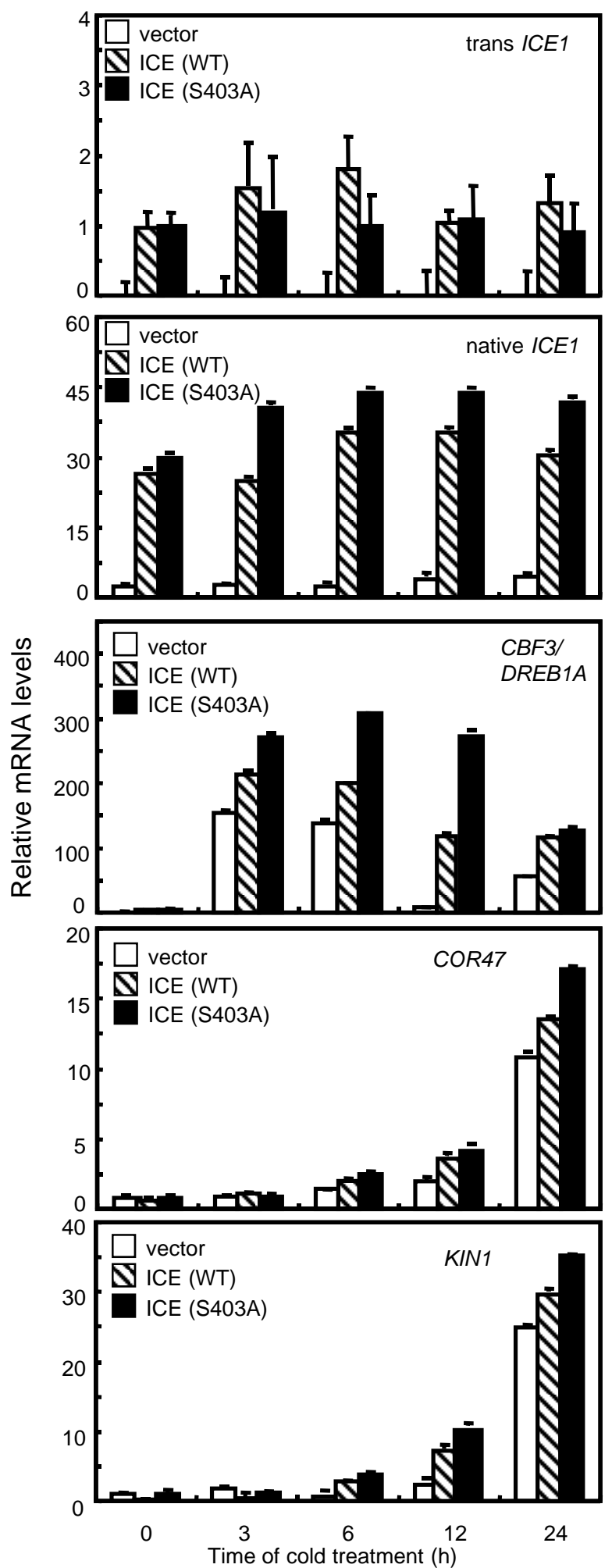

Figure 5 


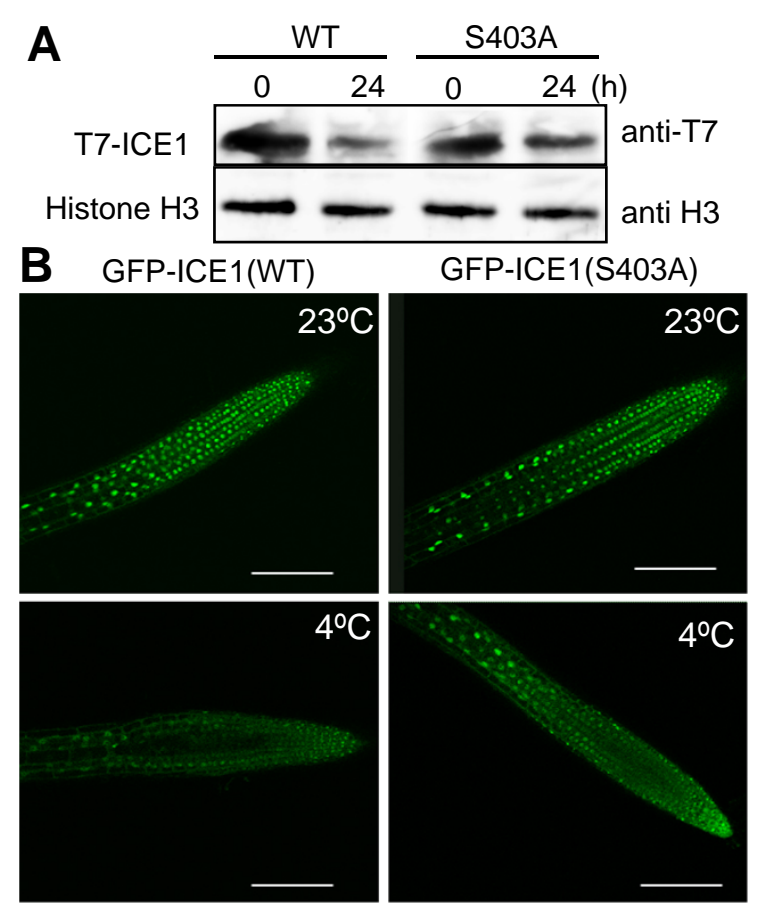

Figure 6 

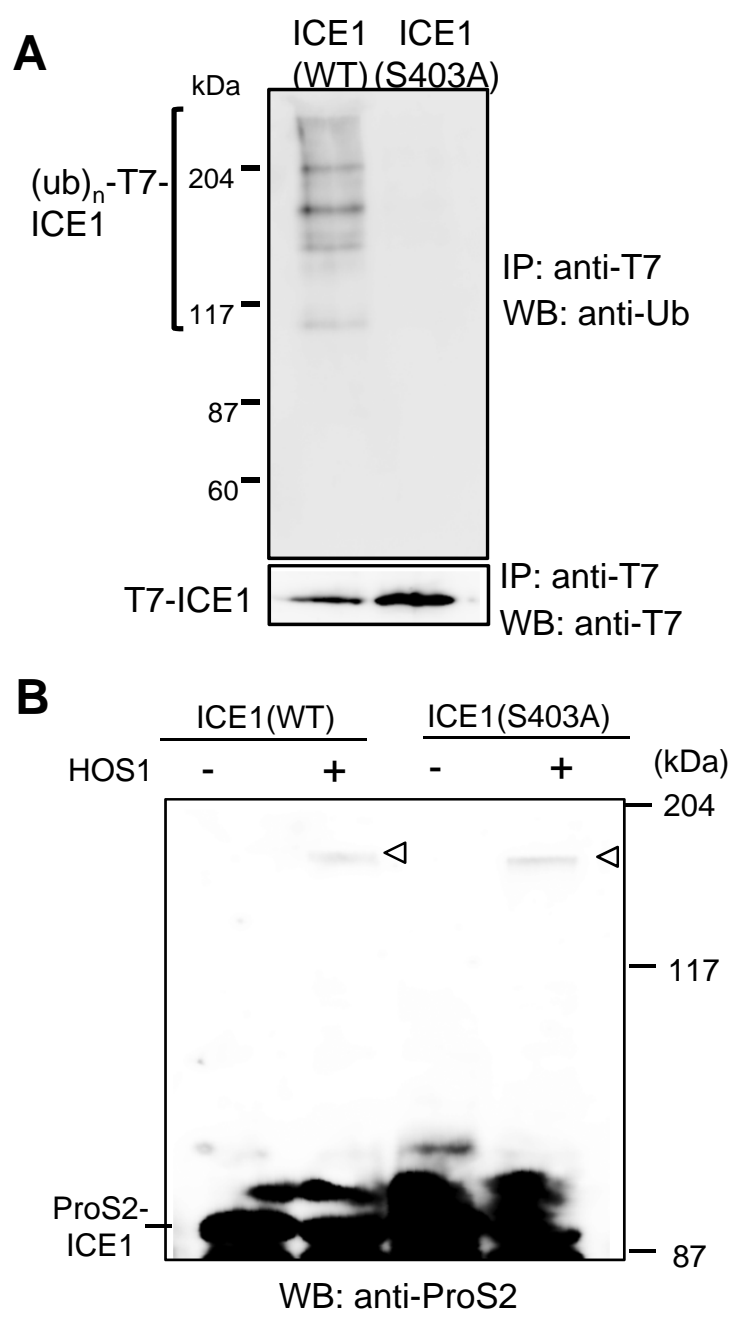

Figure 7 


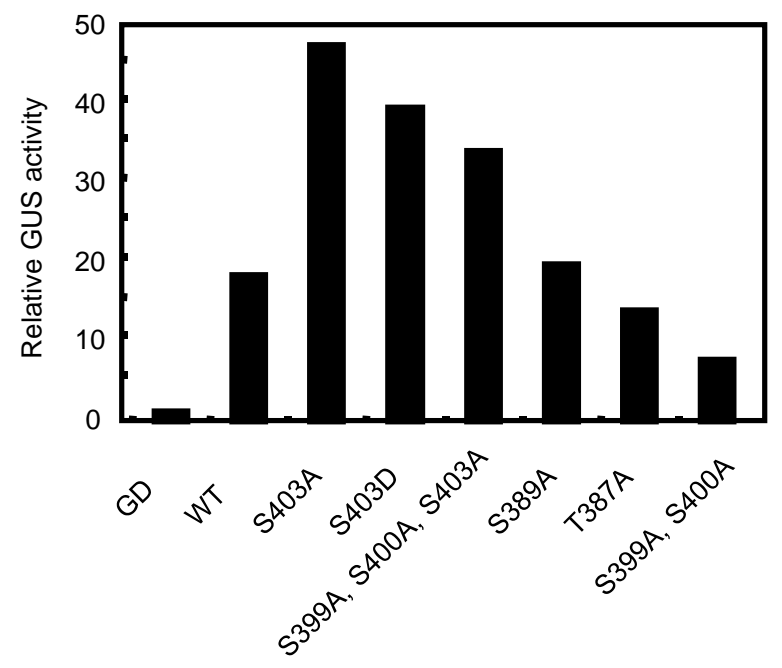

Supplemental Figure S1 


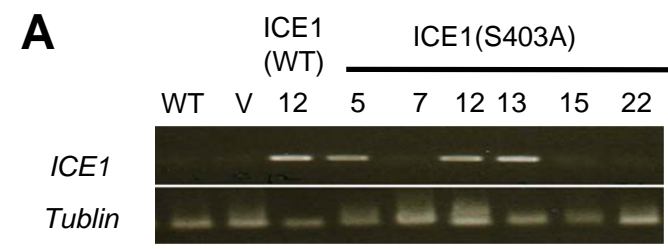

B
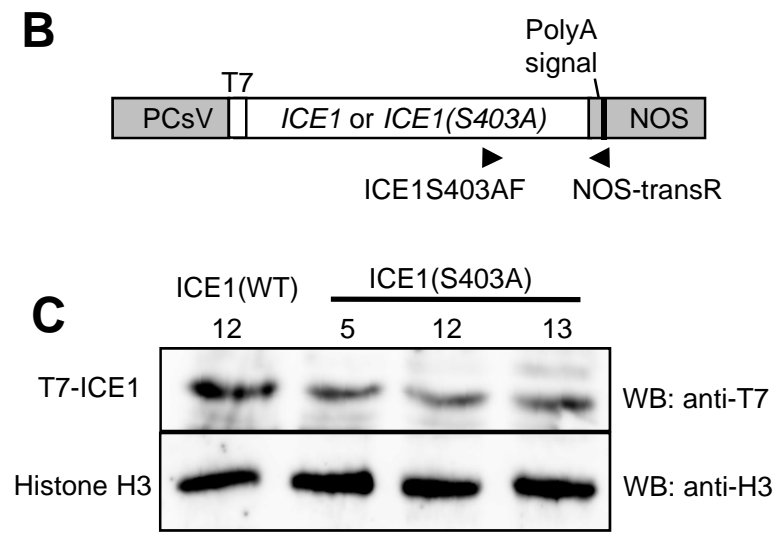

Supplemental Figure S2 


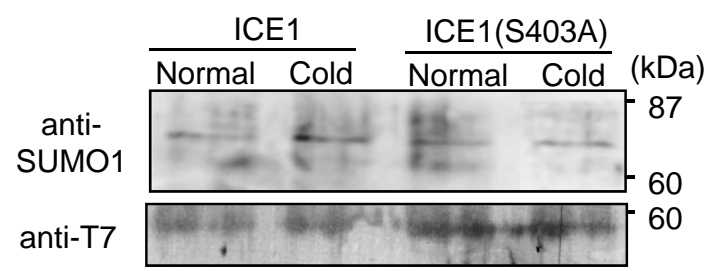

Supplemental Figure S3 
393

403

ICE1 TPQTLSCRVKEELCP -SSLPSPKGQQARVE

$* * * * * * * * * * * * * * * * * * * * * * * * * * *$

ICE2 TPQTLSCRVKEELYPSSSLPSPKGQQPRVE

348

359

Supplemental Figure S4 
Supplementary Table S1. Primers used for mutagenesis and construction.

\begin{tabular}{|c|c|}
\hline Name of primer & DNA sequence (5'-to-3') \\
\hline \multicolumn{2}{|c|}{ for mutagenesis of ICE1 } \\
\hline ICE1S403AF & СССТСТTСТTTACСAGСТССTAAAGGCC \\
\hline ICE1S403AR & GGCCTTTAGGAGCTGGTAAAGAAGAGGG \\
\hline ICE1S403DF & СССТСТTСТTTAССAGATCCTAAAGGCC \\
\hline ICE1S403DR & GGCCTTTAGGATCTGGTAAAGAAGAGGG \\
\hline ICE1SSSAAAF & GTCCCGCTGCTTTACCAGCTCCTAAAGG \\
\hline ICE1SSSAAAR & CCTTTAGGAGCTGGTAAAGCAGCGGGAC \\
\hline ICE1S389AF & CCGCAAACTCTTGCTTGTCGTGTCAAGG \\
\hline ICE1S389AR & CCTTGACACGACAAGCAAGAGTTTGCGG \\
\hline ICE1T387AF & CCTACACCGCAAGCTCTTTCTTGTCGTG \\
\hline ICE1T387AR & CACGACAAGAAAGAGCTTGCGGTGTAGG \\
\hline ICE1SS399AAF & AAGAGTTGTGTCCCGCTGCTTTACCAAG \\
\hline ICE1SS399AAR & CTTGGTAAAGCAGCGGGACACAACTCTT \\
\hline \multicolumn{2}{|c|}{ for construction of pGD-ICE1 } \\
\hline ICE1-GDF & CACGCCCGGGGATGGGTCTTGACGGAAACAA \\
\hline ICE1-HAR & CCGCTCGAGTCAGATCATACCAGCATACCC \\
\hline \multicolumn{2}{|c|}{ for construction of pCsV-ICE1 } \\
\hline ICE1-expF & CGGGATCCATGGGTCTTGACGGAAACAA \\
\hline ICE1-EGR & CGGGATCCTCAGATCATACCAGCATACCC \\
\hline
\end{tabular}


Supplementary Table S2. Primers used for Real-time PCR and RT-PCR analyses.

\begin{tabular}{ll} 
Name of primer & \multicolumn{1}{c}{ DNA sequence (5'-to-3') } \\
\hline DREB1A/CBF3 & 5'-GATGACGACGTATCGTTATGGA-3' \\
& 5'-TACACTCGTTTCTCAGTTTTACAAAC-3' \\
COR47 & 5'-CAGTGTCGGAGAGTGTGGTG-3' \\
& 5'-ACAGCTGGTGAATCCTCTGC-3' \\
KIN1 & 5'-TGGAGCTGGAGCACAACA-3' \\
& 5'-GACCCGAATCGCTACTTGTTC-3' \\
ACTIN2 & 5'-TAACAGGGAGAAGATGACTCAGATCA-3' \\
& 5'-AAGATCAAGACGAAGGATAGCATGAG-3'
\end{tabular}

To detect expression of ICE1 transgene ICE1S403AF CCCTCTTCTTTACCAGCTCCTAAAGGCC NOS-transR GCCAAATGTTTGAACGATCGGGAA 